- The timing of post placement following root canal treatment is critical to maintain an apical seal to the root filling and provide a coronal seal to the root canal system.

- Appropriate gutta-percha removal and post space preparation is important to prevent unnecessary weakening of the root dentine, damage to the periodontium and post perforation.

- Within the limitations of root length, curvature and maintaining 4-5 mm of apical guttapercha for an apical seal, post length is critical to retention of post-retained crowns.

- Preservation of coronal tooth tissue is important in order that a ferrule can be created, reducing the risk of root fracture.

\title{
Tooth preparation for post-retained restorations
}

\author{
D. N. J. Ricketts, ${ }^{1}$ C. M. E. Tait, ${ }^{2}$ and A. J. Higgins ${ }^{3}$
}

\begin{abstract}
Failure of root canal treatment and/or post crowns can be avoided in many cases if appropriate tooth preparation is carried out. This paper discusses the rationale for the timing of post placement following root canal treatment and appropriate methods for removal of gutta-percha prior to post space preparation. The basic principles of post space preparation are described, which should reduce the risk of weakening the root unnecessarily, causing damage to the periodontium and post perforation.
\end{abstract}

\section{RESTORATION OF THE ENDODONTICALLY TREATED TOOTH}

1. Restoration of the rootfilled tooth: pre-operative assessment

2. Tooth preparation for post-retained restorations

3. Post and core systems, refinements to tooth preparation and cementation

4. Weakened anterior roots - intraradicular rehabilitation

1*Senior Lecturer/Hon Consultant in Restorative Dentistry, Dundee Dental Hospital and School, Park Place, Dundee, DD1 4HR.

${ }^{2}$ Lecturer in Endodontics, Dundee Dental Hospital and School, Park Place, Dundee, DD1 4HR. / Specialist Private Practice, Edinburgh,

3Vocational Trainee, Falkirk, Scotland ${ }^{*}$ Correspondence to: David Ricketts, Dundee Dental Hospital and School, Park Place, Dundee, DD1 4HR.

\section{Refereed Paper}

doi: $10.1038 /$ sj.bdj.4812249

๑ British Dental Journal 2005; 198 :

463-471

\section{INTRODUCTION}

Teeth that have received post-retained restorations can fail for a variety of reasons including loss of retention, vertical root fracture, root perforation and failure of the root canal filling. Many of these failures can be avoided with a thorough pre-operative assessment and appropriate tooth preparation. The pre-operative assessment of a tooth that has previously been root filled by another dentist, or by the same dentist some years ago, has been discussed in the first of these publications. However, dentists are frequently faced with the dilemma of how long to wait, following root canal treatment, before a definitive restoration is placed. In some cases this will be a post and indirect restoration which has a relatively high financial cost to the patient. Retrievability is a concern if the endodontic treatment is unsuccessful. As such, many dentists want to establish the success of the endodontic treatment first. But is this approach logical and appropriate?

\section{WHEN SHOULD THE DEFINITIVE RESTORATION BE PLACED? \\ The success rate of endodontics}

Carefully controlled clinical studies have evaluated the success rate of conventional endodontic treatment based upon radiographic evaluation. These have shown that between $83 \%$ and $94 \%$ of treatments are successful. ${ }^{1}$ However, data from epidemiological studies paints a bleaker picture, with only a 61-77\% success rate. An explanation for the difference may lie in the fact that the former root treatments were carried out under carefully controlled environments in either specialist practice or dental schools. Today, the success rate amongst General Dental Practitioners may be better, as the majority of the studies reviewed predate 1990 and since then knowledge and techniques for root canal preparation have improved. In addition, in some studies the observation period was low, varying from as little as six months to ten years. ${ }^{2}$ Clearly six months is inadequate follow-up and the European Society of Endodontology suggest radiographic assessment after one year and if complete healing has not occurred, follow-up for four years. Only then is an asymptomatic root canal treated tooth with a persistent periradicular radiolucency condemned a failure. ${ }^{3}$

Four years is obviously an unacceptable time to wait before placing a definitive restoration and cross-sectional studies have shown that the technical quality of the finally obturated root canal is strongly correlated with the success of the root filling. ${ }^{4,5}$ Short or over-extended root fillings or those with an incomplete apical seal have been found to be associated with higher failure, as have re-treatment cases. $^{5-9}$ Whilst these factors can be evaluated, resolution of an 
Fig. 1. Periapical radiograph of tooth 47 showing a poor coronal seal distally to the crown and core potentially allowing bacteria and bacterial endotoxins access to the root filling and root canal system. This could account for the periradicular periodontitis associated with the distal root. The fractured instrument in one of the mesial root canals may additionally lead to a poor apical seal and associated periradicular periodontitis.

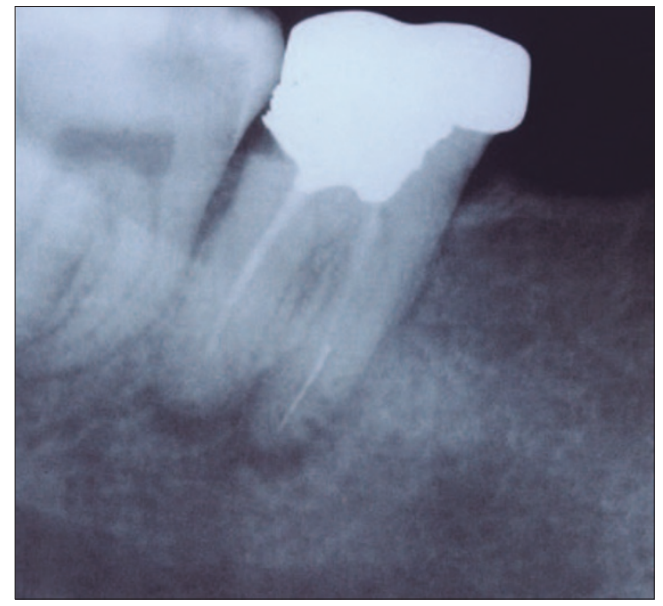

apical lesion will occur even in the absence of a root filling, ${ }^{10}$ provided all the infected root canal tissue is removed and ingress of bacteria is prevented by a coronal restoration which provides a bacterial seal. Patients who present with a root canal filling placed by another dentist therefore pose a problem, as the dentist will be unsure if an aseptic technique was used to prepare and irrigate the root canal; the use of rubber dam and copious amounts of antibacterial irrigant, such as sodium hypochlorite, being of paramount importance.

A final factor to be borne in mind when determining the prognosis of a root canal filling is whether there was a periradicular lesion present prior to root treatment. The success rate can fall from 96\% where there was no pathology evident to $86 \%$ where there was a periradicular lesion. ${ }^{5}$

These features, such as the knowledge of an aseptic root canal preparation, obturation to achieve an apical and coronal seal, and no evidence of pre-operative periradicular pathology can be accompanied by a good prognosis and delaying post placement serves no purpose.

\section{Coronal versus apical seal}

Historically, endodontists have paid great importance to the creation and maintenance of an apical seal during obturation and post space preparation. ${ }^{11}$ The effect of preparation technique, ${ }^{12}$ irrigant, ${ }^{13}$ removal of the smear layer, ${ }^{14}$ how the root canal is dried, ${ }^{15}$ which obturation technique is used ${ }^{16}$ and which sealer has been used ${ }^{17-22}$ have all been investigated with regard to the integrity of the apical seal of a root canal filling. Most of these laboratory studies have used dye penetration techniques to assess the apical seal, however, a recent study of 116 teeth root canal treated in vivo and extracted at least six months later, has cast doubts as to the clinical relevance of the apical seal. ${ }^{23}$ In this study all of the teeth demonstrated dye leakage irrespective of whether the endodontic treatment was deemed to be successful or not. With this in mind there is mounting evidence to suggest that for a successful root canal filling the coronal seal provided by the final restoration is as, if not more, important than the apical seal of the root canal filling. ${ }^{24,25}$ A restoration with a poor coronal seal (Fig. 1) will potentially allow saliva, bacteria and endotoxins access to the root canal and possible penetration along its entire length leading to periradicular periodontitis. ${ }^{25-33}$ The endotoxins alone can predictably move through an obturated root canal and so bacteria around a defective coronal restoration, could theoretically sustain a periradicular inflammation. ${ }^{26}$

In reality, Ray and Trope (1995) ${ }^{34}$ have shown that in 1,010 endodontically treated teeth, examined radiographically, the quality of the coronal restoration is more important than the endodontic treatment for apical periodontal health. However, in this study none of the coronal restorations were post retained. This was addressed by Fox and Gutteridge (1997) ${ }^{35}$ in a laboratory study. They investigated cast post and cores cemented with zinc phosphate cement, preformed stainless steel (Paraposts, Whaledent Inc. NY, USA) posts cemented with a resin luting cement and composite core, and finally an aluminium temporary post (Parapost) with a polycarbonate temporary crown (Directa) filled with self-curing acrylic (Trim), cemented with a temporary luting cement. It was shown that there was no significant difference in the coronal leakage around cast post and cores and the preformed stainless steel posts and composite cores. However, the temporary post crowns demonstrated significantly more leakage than the permanently cemented posts. The authors therefore suggest immediate restoration of the tooth with a pre-fabricated post and composite core, as the need for a temporary post crown is unnecessary. If temporary post crowns are used, they should have a good marginal fit and only be left in place for as short a time as possible.

\section{Advantages of immediate post placement}

Following obturation of the root canal, immediate preparation for post placement has a number of additional advantages. The operator has greater familiarity with the root canal morphology and its working length, and there is less risk of coronal tooth tissue fracturing, so losing the reference point from where the working length was determined. This leads to the appropriate amount of gutta-percha removal and less risk of post perforation.

Concerns that early preparation is likely to disrupt the apical gutta-percha seal can be dispelled as the reverse is true. ${ }^{36,37}$ Fan et al (1999) ${ }^{36}$ found more apical leakage after delayed post preparation compared with immediate preparation and removal of laterally compacted gutta-percha with either AH26 or Pulp Canal sealer. In a similar dye leakage study, immediate preparation of canals obturated with guttapercha and a zinc oxide-eugenol based sealer also resulted in less apical leakage. ${ }^{37}$ This has been attributed to less 'pulling' effect that mechanical removal of gutta-percha may have on setting sealer compared to set sealer. 


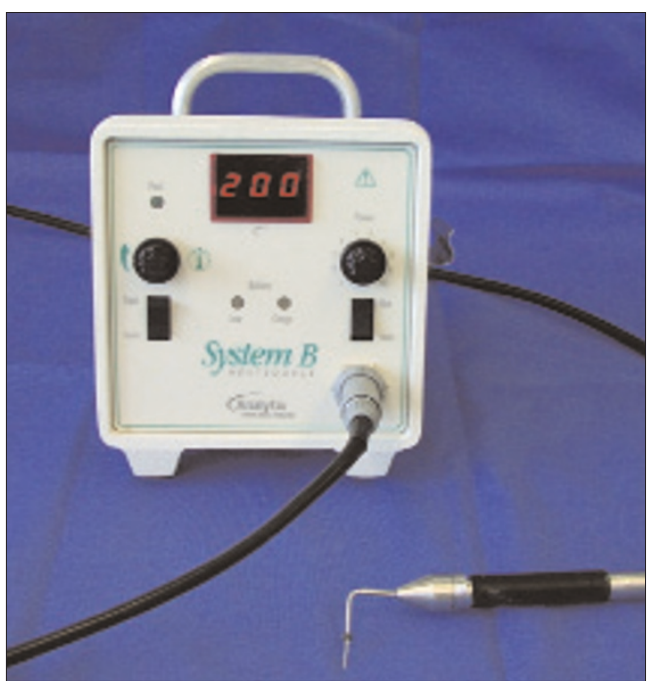

Fig. 2. System $B$ with heated plugger $\left(200^{\circ} \mathrm{C}\right)$ in foreground, with rubber stop placed at the desired length for gutta-percha removal.

\section{REMOVAL OF ROOT FILLING MATERIAL IN PREPARATION FOR POSTS \\ Obturation techniques}

Gutta-percha is today the universally accepted core material used for root canal obturation. However, the techniques for placement differ, but all require the use of a sealing cement. Obturation techniques include cold lateral compaction of gutta-percha points, compaction of gutta-percha that has been heat softened in the canal and compacted (eg System B), thermoplastisised gutta-percha which is injected into the canal (eg Obtura and UltraFil) and finally compaction of gutta-percha which has been placed in the canal and softened by mechanical means (eg McSpadden compactors). These obturation techniques are unlikely to have an impact on the final apical seal once post space preparation has been carried out. ${ }^{38}$ An alternative obturation technique also exists which involves heated gutta-percha surrounding a plastic or metal carrier (eg Thermafil). The carrier ensures that the gutta-percha passes to the correct working length and is left in situ with the gutta-percha. During mechanical gutta-percha removal of this system, there is greater potential to disrupt the apical gutta-percha and a number of dye leakage studies have supported this hypothesis. ${ }^{39-41}$ It would therefore be prudent not to use such obturation techniques if placement of a post is anticipated.

\section{Chemical removal}

Solvents such as oil of eucalyptus, oil of turpentine and chloroform have been used to soften gutta-percha for removal, with the latter two being the most effcicient. ${ }^{42}$ However, some of these materials and especially chloroform are hazardous to use as they are toxic and potentially carcinogenic. ${ }^{42,43}$ Oil of turpentine is less toxic, but there is concern that solvents in general lead to a dimensional change in the gutta-percha, leading to increased microleakage. ${ }^{44,45}$ This together with the fact that it is difficult to
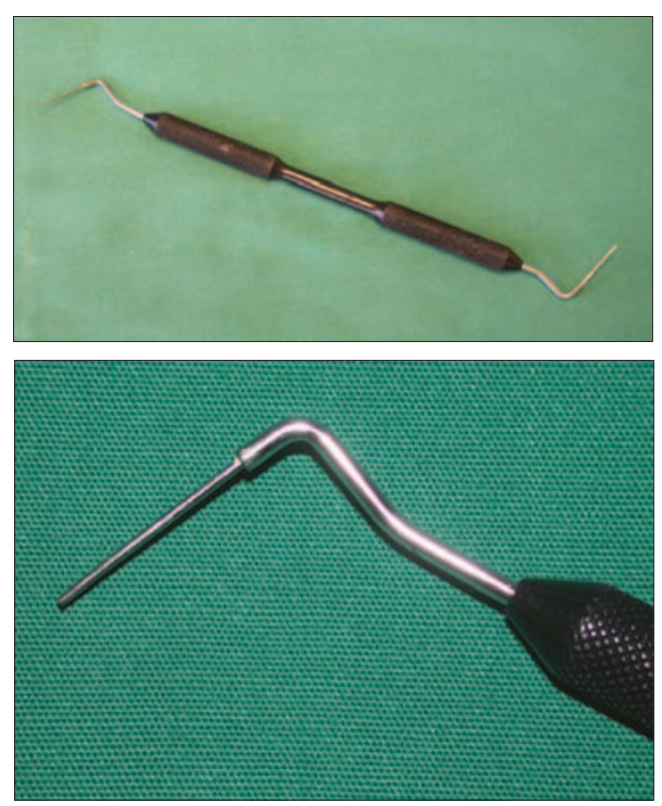

Fig. 3. Buchanan plugger.

control the depth of softening of the gutta-percha and potential leakage of the solvents into the periradicular tissues should be sufficient to discourage their use for gutta-percha removal for post placement. They are however a necessary adjunct in root canal re-treatment cases.

\section{Thermal removal}

A heated instrument such as a lateral compactor can be inserted into the gutta-percha to the desired length to soften and remove the guttapercha. However, in narrow canals, fine instruments lose their heat quickly and gutta-percha removal can be difficult. ${ }^{46}$ A System B spreader is ideal for removal of gutta-percha (Fig. 2). From a pre-operative radiograph a plugger should be chosen of the correct dimensions that is likely to bind at the desired post length and this position should be marked on the plugger with a rubber stop. The tip should be placed in the gutta-percha and with the heat applied driven slowly to the desired post length in about 2-3 seconds. The heat should be removed and the plugger allowed to cool for about 7-10 seconds, twisted and then removed with the coronal gutta-percha. Alternatively, a short burst of heat to the plugger will allow for easy removal. It is important that the plugger is sufficiently hot to completely soften the gutta-percha. If too cool, it will result in the gutta-percha remaining sticky with the risk of dislodging the apical gutta-percha. An instrument such as a Buchanan plugger (Fig. 3) can then be used to vertically compact the softened gutta-percha. Such a technique is useful in removing old gutta-percha which can become quite hard. ${ }^{47}$

Some authors would suggest that guttapercha should be removed with heated techniques as a routine and mechanical removal only used if heat is insufficient. ${ }^{48}$ If mechanical removal is used, a heated instrument can be used to soften the most coronal gutta-percha, so that it can be vertically compacted and adapted to the canal walls to create a seal. 


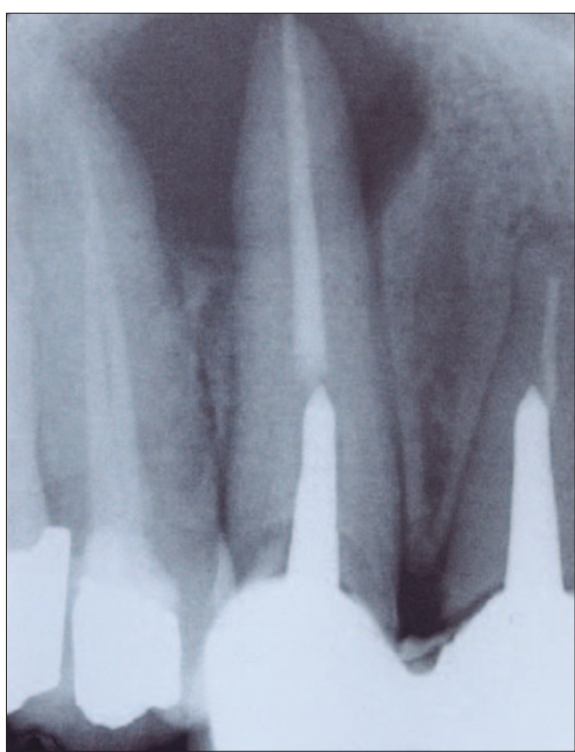

Fig. 4. Periapical radiograph showing teeth 13 and 12 used as double abutments for a fixed-fixed conventional bridge. Both retainers are poorly fitting. Inappropriate use of an end cutting twist drill has led to a post preparation in tooth 12 , distal to the original root canal, weakening the tooth unnecessarily.

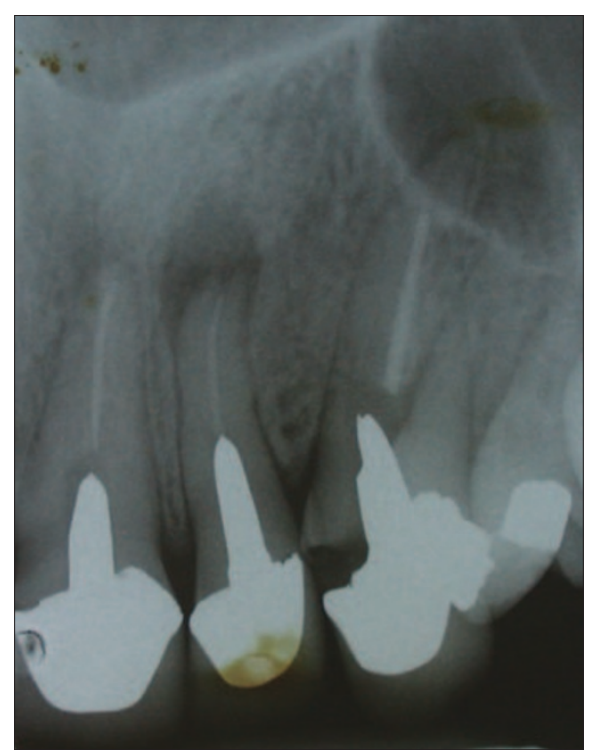

Fig. 5. Periapical radiograph of tooth 23 with a post that poorly fits the prepared post hole. The post hole preparation is of excessive diameter and incorrect angulation resulting in near root perforation and a severely compromised root. This tooth has had to be reinforced using the system to be described in the fourth paper in this series.

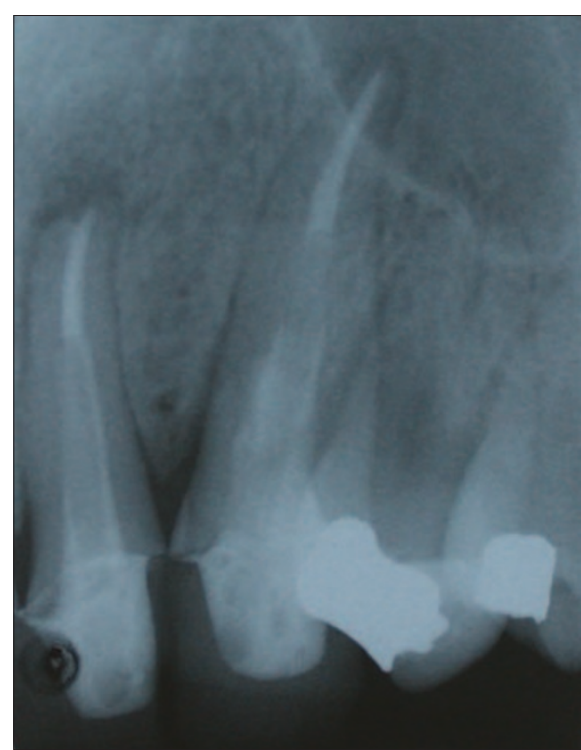

Fig. 6. Tooth 23 shown in Figure 5, following internal rehabilitation, using the Luminex post system described in the fourth paper in this series. Tooth $\mathbf{2 2}$ has also been re-treated in a similar manner.

\section{Mechanical removal}

Mechanical removal of gutta-percha is efficient and probably the most commonly used technique, but it is a technique that can result in the most damage to tooth tissue. If done incorrectly, it can weaken the root unnecessarily, damage the periodontium and in some cases lead to root perforation (Figs 4-6). A non-end cutting bur such as a Gates-Glidden or Peeso reamer should be used for gutta-percha removal, as these will cut and remove the relatively softer gutta-percha preferentially to the dentine of the canal walls.

The sequence in which the burs are used is important so that a rise in temperature at the root surface, which could damage periodontal cells, is avoided and the risk of preferentially cutting away root dentine to one side of the root canal is reduced (Fig. 7). Temperature rise on the root surface has been investigated in a number of studies. ${ }^{49-51} \mathrm{~A}$ Gates-Glidden bur rotating at 8,000 rev $\mathrm{min}^{-1}$ results in a small rise in temperature at the root surface. However, both tapered and parallel-sided post drills produce a significant increase in temperature in excess of $17^{\circ} \mathrm{C} .{ }^{49}$ Peeso reamers also generate significant rises in temperature, higher than that reached with Gates-Glidden burs and Parapost twist drills. ${ }^{50}$ To reduce this temperature increase, which could potentially damage cells in the periodontal ligament, it is important that the smaller sized Gates-Glidden burs are used first, working up through the sizes in turn, until no gutta-percha is removed apically. At this stage the smallest post drill can be used, again working up through the size sequence until the final post size is reached.

\section{POST SPACE PREPARATION}

\section{How long and wide should the post be?}

Whilst comparisons have been made between coronal and apical seal, the aim of a successful restoration would be to ensure that the entire root canal from apex to crown provides a bacterial and fluid-tight seal. A number of studies have investigated apical seal following post space preparation and it would appear that 4-5 mm of gutta-percha should remain apically. ${ }^{52-56}$ This is the minimum amount of gutta-percha that should remain, however, in certain circumstances such as longer roots more may be left provided the post placed is of adequate length for retention.

The issue of remaining gutta-percha cannot be divorced from the length of post. The longer the post length the less apical gutta-percha remains and the length of post is critical where retention is concerned: the longer the post, the better the retention. ${ }^{57}$ Various rules have been suggested for passively fitting posts, such as the post length should be as long as, if not longer, than the clinical crown height and that the post should end halfway between the crestal bone and the root apex. ${ }^{58}$ The post should therefore be as long as possible bearing in mind limitations such as root length, root morphology (root curvature) and, of paramount importance, maintenance of the apical seal. Short posts not only have poor retention, but also transmit larger lateral forces to the remaining root structure compared to longer posts. ${ }^{59}$ With the wealth of literature supporting the use of longer posts, it is surprising that in a study of 200 endodontically treated teeth, half had posts extending one-third or less into the root. ${ }^{60}$

\section{POST DIAMETER}

Increasing post length is more important than increasing post diameter for improvement in post retention. ${ }^{61}$ Adequate width is obviously 


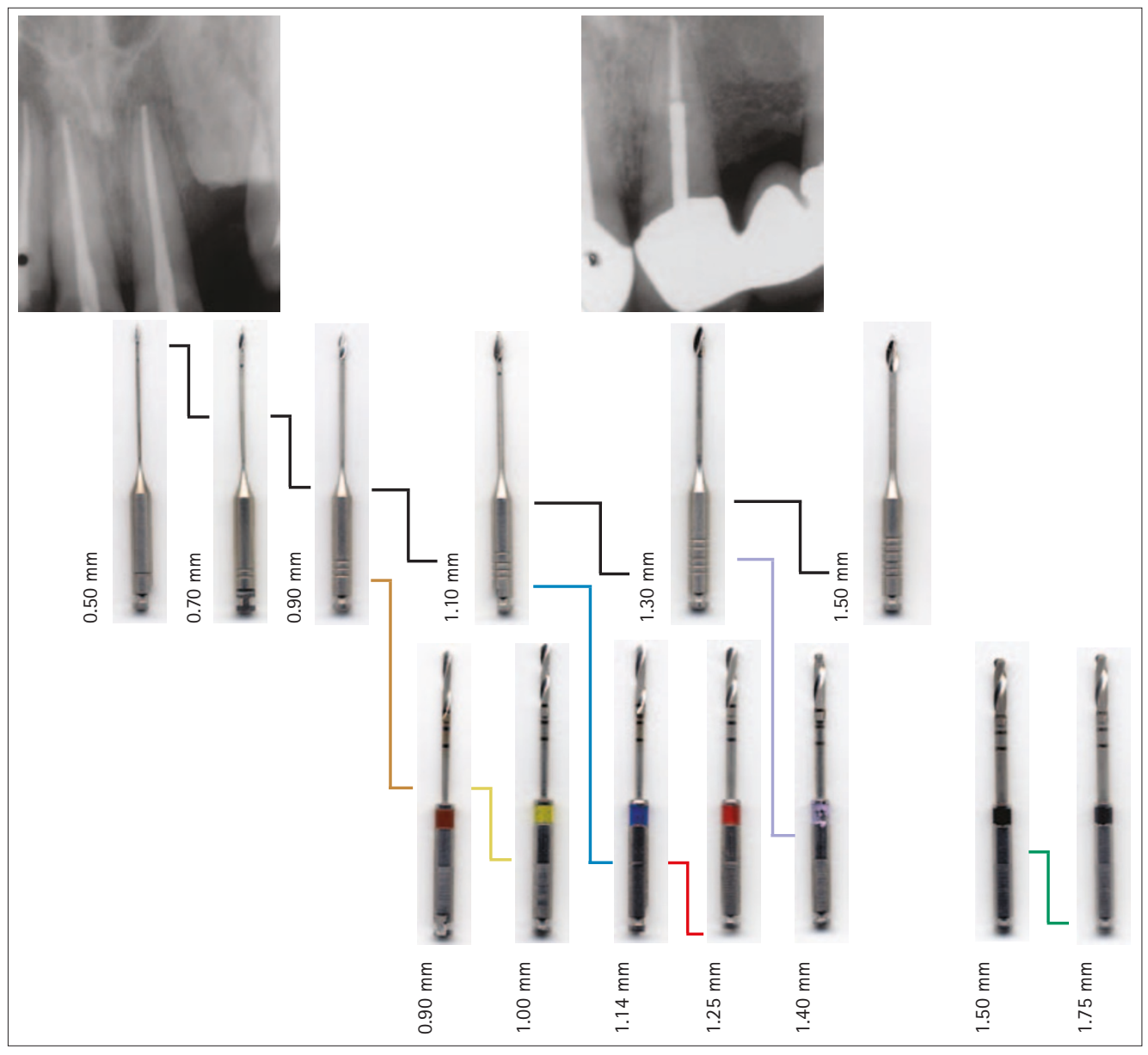

important for post strength and resistance to post fracture, however, wider posts lead to an increased risk of lateral root perforation, introduce greater cervical stresses ${ }^{62}$ within the root structure, lead to a reduction in impact resistance, and decreased resistance to root fracture. ${ }^{63}$ The potential for root fracture is exacerbated when threaded posts are used. ${ }^{64}$ Therefore, work has been carried out to determine the optimum post diameter and it has been suggested that a post should not exceed $1 \mathrm{~mm}$ in diameter at its tip. ${ }^{65}$ The more dentine remaining buccal to the post, the less prone the root is to fracture under horizontal impact. ${ }^{66}$ However, teeth obviously vary in diameter and a post diameter less than $1 \mathrm{~mm}$ would be recommended for lower incisor teeth, for example. It is important that when viewing preoperative radiographs root morphology is borne in mind, as a lower incisor may appear a certain width radiographically, but this tooth has a root with a mesial and distal concavity in cross-section. This is also true of upper second premolar teeth and in those rare occasions a post is required in a lower molar tooth, the distal root. These roots therefore are narrower than they appear radiographically and this is compounded by the fact that the radiograph is a slightly magnified image.

A more sensible approach would be that the diameter of the post at its tip should be no greater than one-third of the diameter of the root at the corresponding depth. ${ }^{58}$ Using this rule, it has been shown that the post diameter should be approximately $0.6 \mathrm{~mm}$ in diameter for a lower incisor $^{67}$ and $1 \mathrm{~mm}$ for an upper incisor and canine teeth, with $0.8 \mathrm{~mm}$ diameter posts suitable for most teeth. Again the sequential use of post twist drills must be emphasised, always starting with the narrowest, working up to the desired post diameter, so reducing the temperature rise at the periodontium and reducing the risk of preferentially cutting to one side of the root canal, leading to possible root weakening and perforation.

\section{REMAINING CORONAL TOOTH TISSUE - CREATING THE FERRULE}

It is of paramount importance that as much coronal or supragingival tooth tissue is preserved as possible, as this significantly restoration. Between 1-2 $\mathrm{mm}$ of tooth tissue coronal to the finish line of the crown preparation (Fig. 8) significantly improves the fracture resistance of the tooth and is more important than the type of material the core and post is made from. ${ }^{68}$ The band of extra-coronal material (usually metal or metal ceramic) that encompasses this tooth tissue is termed the ferrule and is usually provided by the crown that is placed over the post and core system, but can be provided by a cast post and core which incorporates a diaphragm or coping. The term ferrule is thought to be derived from the Latin word ferrum, meaning iron, and viriola, meaning improves the prognosis of the tooth and
Fig. 7. Periapical radiograph of root filled central incisor teeth (top left) from which the diameter of the post to be used can be estimated. During post space preparation the GatesGlidden burs (with the diameter adjacent to the latch grip) should be used in sequence to remove the gutta percha. The diameter of the posts in the system to be used should be known (here the Parapost twist drills are illustrated together with their diameter). The Gates-Glidden burs should be used until the operator can transfer to the appropriate Parapost drill. This procedure leads to appropriate post space preparation as can be seen top right. 
Fig. 8. Two examples of teeth that require posts to retain cores, the top with a 2-3 $\mathrm{mm}$ ferrule and the lower with no ferrule. The tooth with the ferrule has a much better prognosis than the one without.
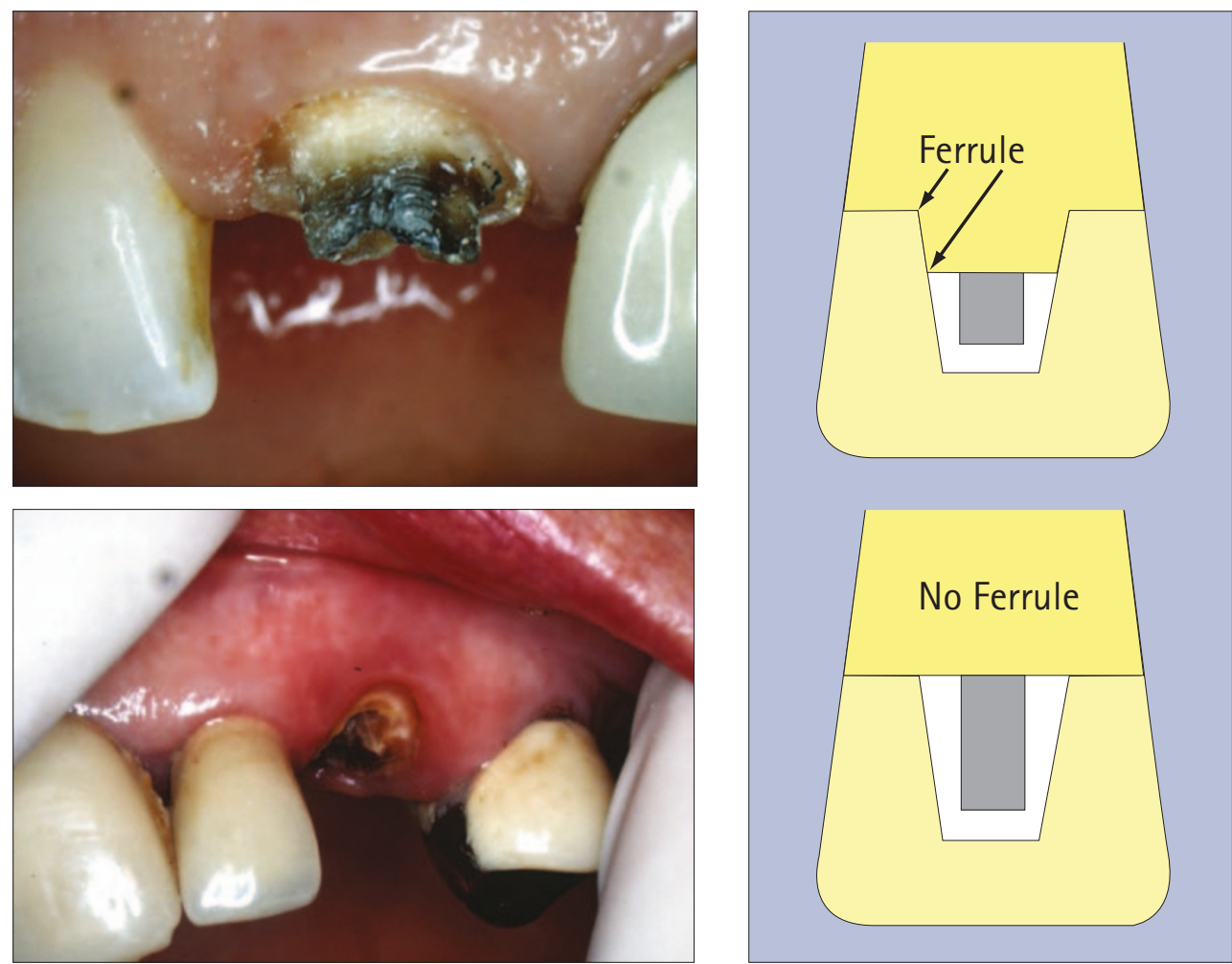

bracelet. $^{69}$ Thus the ferrule effect occurs because of the crown bracing against the remaining supragingival tooth tissue.

Some authors have questioned the benefit of the ferrule ${ }^{66}$ however the majority of the literature would support its importance in reducing root fracture due to functional lever and torsional forces, and the wedging effect of tapered posts. ${ }^{70-78}$ Barkhordar et al in $1989^{72}$ compared restored teeth that were prepared with and without a ferrule and showed that the ferrule reduced vertical root fracture by one-third. When failure occurred in teeth with a ferrule, the failure was most commonly due to horizontal fracture compared to the vertical root fracture seen in teeth with no ferrule. Thus the teeth were more likely to be retrievable.

In 1990, Sorensen and Engleman suggested that the failure rate of post crowns was significantly reduced if $1 \mathrm{~mm}$ of coronal tooth tissue remained. ${ }^{70}$ However, a more recent study by Libman and Nicholls (1995) investigating the effect of cyclic loading on cast post and cores with ferrules $0.5 \mathrm{~mm}, 1 \mathrm{~mm}, 1.5 \mathrm{~mm}$ and $2 \mathrm{~mm}$ high, has shown that the $1.5 \mathrm{~mm}$ and $2 \mathrm{~mm}$ ferrules led to failure at a much higher number of cycles. ${ }^{73}$ A similar laboratory study also supports increased fracture resistance afforded by ferrules 1.25-2.5 mm. ${ }^{74}$ The height of the ferrule at differing locations around the circumference of the tooth may also be important due to functional occlusal loading. Thus a maxillary incisor would benefit from a longer ferrule on the palatal aspect and a mandibular incisor on the labial aspect. ${ }^{75}$ Thus a $1.5 \mathrm{~mm}$ ferrule can be recommended labially and lingually whereas a shorter $1 \mathrm{~mm}$ ferrule could be accepted mesially and distally due to decreased stress in these directions.

Whilst most studies on the failure of post crowns have been carried out in the laboratory, little evidence exists from clinical randomised controlled studies. One retrospective clinical study which evaluated 788 post crowns radiographically concluded that post fractures occurred in teeth with a lack of a ferrule at the crown margin. ${ }^{76}$ However, insufficient data is given in this study as to how many teeth had a ferrule and how many did not. In addition, the extent of any coronal tooth tissue could not be estimated from the radiographs as the metal ferrule would have masked this. Despite the lack of clinical studies, the best evidence available supports the importance of the ferrule.

Because the amount of coronal tooth tissue is considered essential for success of post crowns, consideration should be given to the marginal preparation. A shoulder preparation could compromise this or even lose the ferrule effect completely. In these situations a champher finish for a gold crown or a metal ceramic crown with a metal collar may be preferable. However, this will be dictated by the patient's smile line and the appearance of the crown.

\section{Insufficient coronal tooth tissue for a ferrule} If insufficient coronal tooth tissue remains there are a number of alternative treatment options available:

- orthodontically extrude the root;

- crown lengthen;

- accept poorer prognosis and place a post crown without an adequate ferrule;

- extract and replace with a fixed or removable prosthesis. 


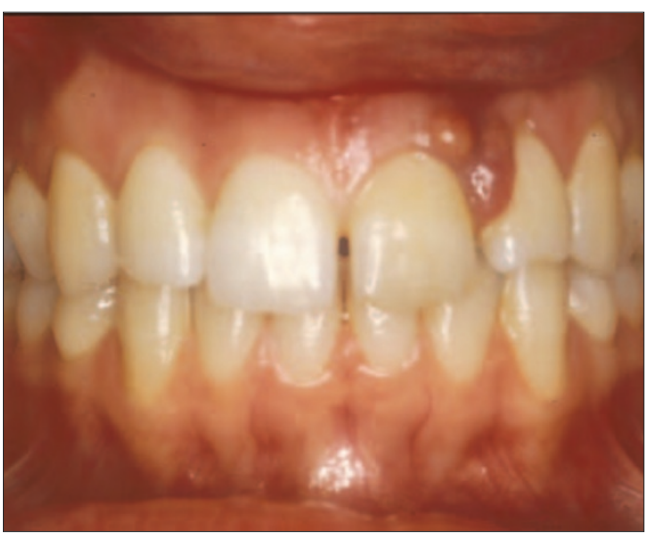

\section{Orthodontic extrusion}

This procedure requires a significant amount of additional treatment over a prolonged period. Consider the patient in Figure 9 who has lost coronal tooth tissue of the upper left central incisor due to trauma. The tooth had previously been root canal treated as a result of previous trauma. To extrude the root, a modified post has to be cemented into the root canal to enable attachment of the orthodontic elastics (Fig. 10). Such a procedure has a number of disadvantages:

- The circumference of the extruded root face is narrower due to the taper of the root (Fig. 10) and therefore the emergence profile of the crown is compromised, requiring excellent oral hygiene (Fig. 11).

- Sufficient extrusion of the root to allow an additional $1.5 \mathrm{~mm}$ ferrule results in a shorter root within the alveolus and a lower crown to root ratio, as such.

- Posts placed are likely to be shorter than the desired length for optimum retention.

\section{Crown lengthening}

Crown lengthening necessitates raising a buccal and lingual mucoperiosteal flap and removal of crestal alveolar bone. It has been suggested that the crown margins should be placed 2-3 $\mathrm{mm}$ supracrestal to the alveolar bone to avoid subsequent unpredictable inflammation and bone loss, thus preserving the biological width. ${ }^{78}$ To achieve this and a $1.5-2 \mathrm{~mm}$ ferrule means that the crestal bone has to be removed to allow 4.5-5 mm of supracrestal tooth tissue. This again leads to an abnormal crown root ratio, larger interdental spaces and a potential step in the gingival margin profile.

\section{Accept poor prognosis}

To be able to give informed consent, the patient should be given the alternative treatment options and the potential success rates of each. Whilst a tooth with little or no coronal tooth tissue has a poorer long-term prognosis, careful execution and care with the occlusion may provide the patient with a post crown that may last many years. There is some evidence to suggest that the ferrule effect is not as important in relation to root fracture if resin-reinforced, fibrebased posts are used in conjunction with adhesive luting cements. ${ }^{79}$ However, the evidence for

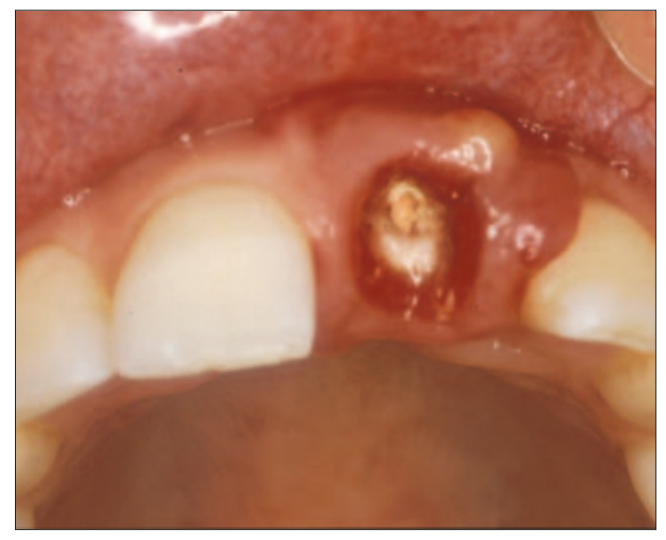

Fig. 9. The root filled tooth 21 has suffered trauma and a subgingival fracture. To place a post crown, with an adequate ferrule the root will require orthodontic extrusion.
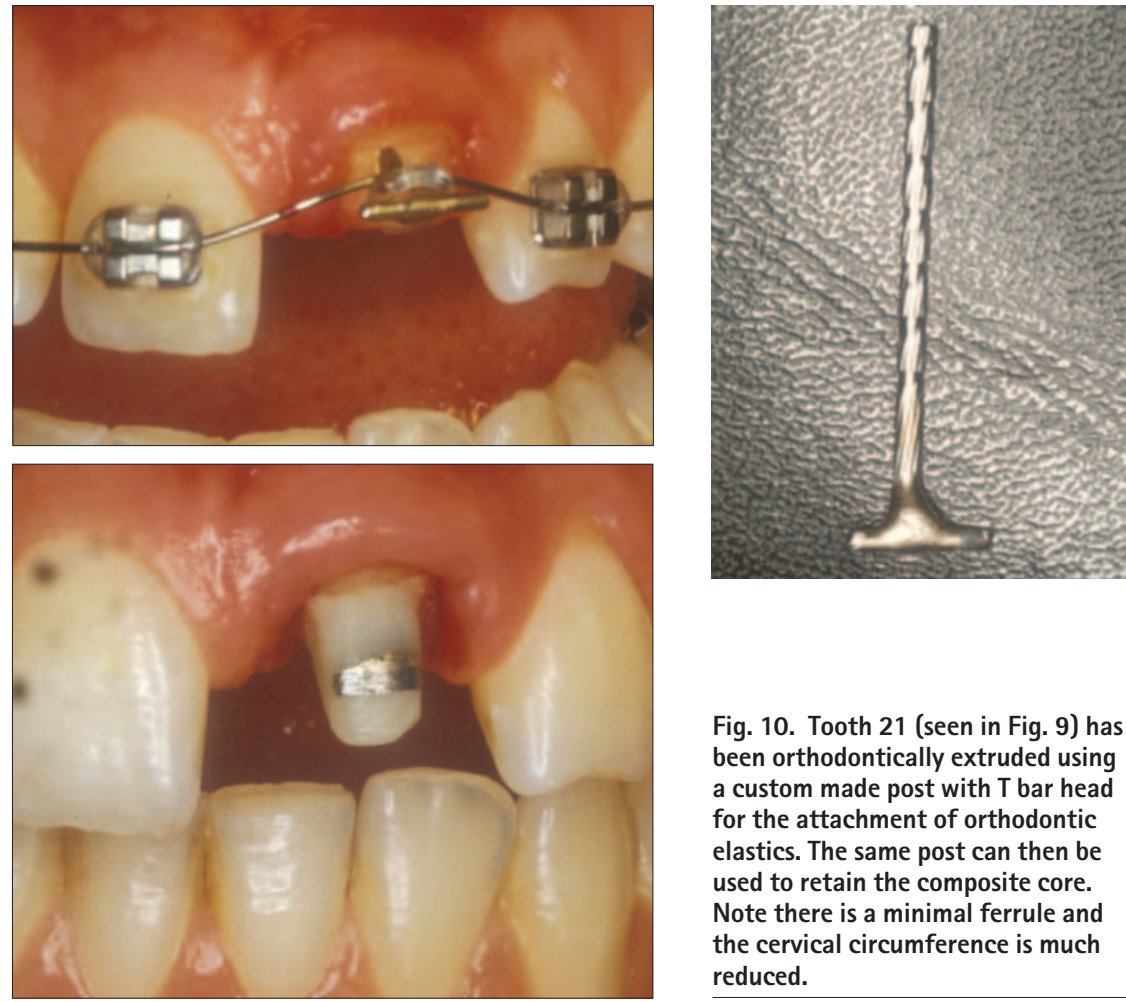

Fig. 10. Tooth 21 (seen in Fig. 9) has been orthodontically extruded using a custom made post with $T$ bar head for the attachment of orthodontic elastics. The same post can then be used to retain the composite core.

Note there is a minimal ferrule and the cervical circumference is much reduced.
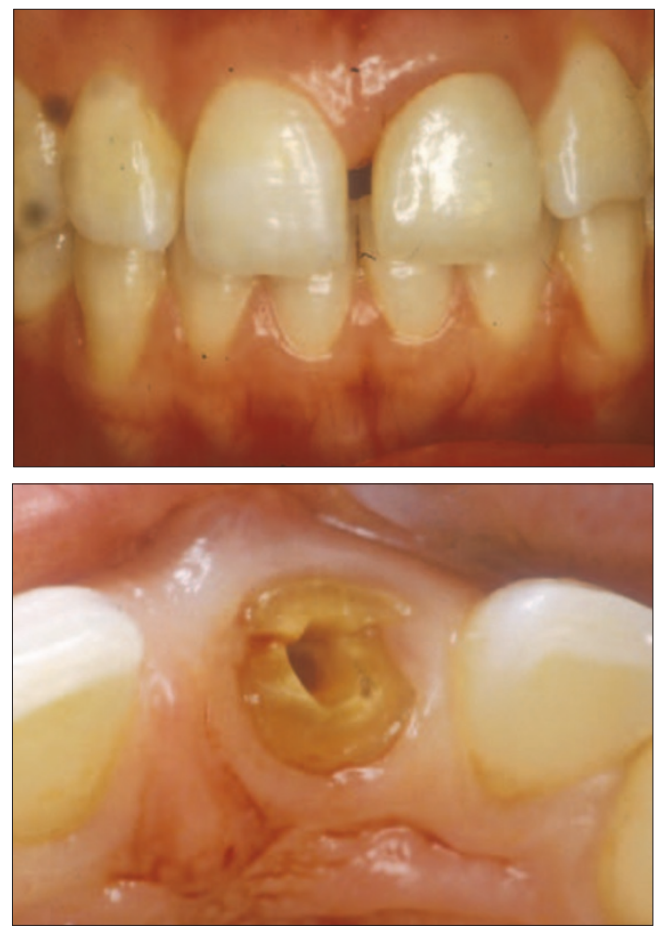

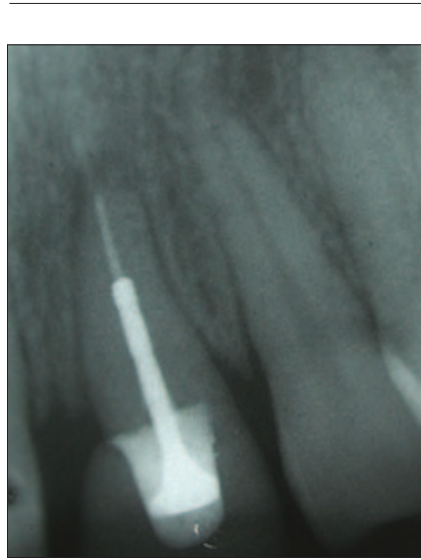

Fig. 11. Tooth 21 (seen in Figs 9 and 10) with cemented crown having an over-contoured emergence profile to produce an acceptable appearance. This requires excellent oral hygiene to maintain gingival health. The periapical radiograph shows that the post is shorter than the ideal, this together with the lack of ferrule has led to a vertical root fracture two years following placement. 
this is limited and whatever post is used in the absence of a ferrule, the patient may have repeated problems of decementation or root fracture. Thus the patient must be aware of this prognosis, however, the alternatives will also have drawbacks and disadvantages.

\section{Extraction}

For a patient with a post crown of poor prognosis, in an otherwise well-cared for dentition, with no active periodontal disease or caries, extraction and placement of an implant may be the preferred and more predictable option. However, there are also simpler, predictable and less costly ways to replace a missing tooth with either a fixed (conventional or adhesive bridge) or removable prosthesis.

\section{CONCLUSIONS}

There are many publications on post crowns within the dental literature, the majority of which are laboratory studies. Care must be taken in extrapolating the results of these to the clinical situation as there are a multitude of variables that exert an influence clinically that cannot be replicated in the laboratory. Some of these include moisture content, moisture control, supporting periodontal structures, differences in occlusal forces and protective pain and proprioceptive responses to name but a few. Laboratory dye leakage studies for example are common, however, their merit and clinical relevance have been questioned.

Carefully planned prospective randomised controlled trials are regarded as providing the best evidence base. However, these are sadly lacking due to the logistics of recruiting and retaining a sufficiently large number of subjects required to demonstrate significant differences between techniques and materials over an acceptably long observation period. This is also compounded by the speed with which new materials are introduced and evolve. Laboratory studies therefore frequently represent the best evidence available and a pragmatic approach is required.

Accepting these limitations, this paper has described the basic principles of tooth preparation for post retained restorations which is supported by the literature. Two of the most important aspects which dictate success are adequate post length and sufficient coronal tooth tissue. Without these the prognosis of the restoration is poor and the patient should be clearly warned that this is the case. There are ways in which the retention of a post of inadequate length can be improved and this will be discussed in the next in this series of publications. In this paper, alternative post and core systems, the refinements to tooth preparation that are required for these and the cementation techniques will also be described.

\section{REFERENCES}

1 Eriksen H M. Epidemiology of apical periodontitis. In Ørstavik D, PittFord T R Essential Endodontology. 1st Edition. Oxford: Blackwell Science, 1998 pp179.

2 Freidman S. Treatment outcome and prognosis of endodontic therapy. In Ørstavik D, PittFord T R Essential Endodontology. 1st Edition. Oxford: Blackwell Science, 1998. pp367-401.
3 Consensus report of the European Society of Endodontology on quality guidelines for endodontic treatment. Int Endod J 1994; 27: 115-124.

4 Kerekes K, Tronstad L. Long-term results of endodontic treatment performed with a standardized technique. J Endod 1979; 5: 83-90.

5 Sjögren U, Hagglund B, Sundqvist G, Wing K. Factors affecting the long-term results of endodontic treatment. J Endod 1990; 16: 498-504.

6 Morse D R, Esposito J V, Pike C, Furst M L. A radiographic evaluation of the periapical status of teeth treated by the gutta-percha - eucapercha endodontic method: a oneyear follow-up study of 458 root canals. Part II. Oral Surg Oral Med Oral Pathol 1983; 56: 89-96.

7 Barbakow F H, Cleaton-Jones P E, Friedman D. Endodontic treatment of teeth with periapical radiolucent areas in a general dental practice. Oral Surg Oral Med Oral Pathol 1981; 51: 552-559.

8 Petersson K, Petersson A, Olsson B, Hakansson J, Wennberg A. Technical quality of root fillings in an adult Swedish population. Endod Dent Traumatol 1986; 2: 99-102.

9 Matsumoto T, Nagai T, Ida K, Ito M, Kawai Y, Horiba N, Sato R, Nakamura H. Factors affecting successful prognosis of root canal treatment. J Endod 1987; 13: 239-242.

10 Klevant F J, Eggink C 0. The effect of canal preparation on periapical disease. Int Endod J 1983; 16: 68-75.

11 Goodacre C J, Spolnik K J. The prosthodontic management of endodontically treated teeth: a literature review. Part II. Maintaining the apical seal. J Prosthodont 1995; 4: 51-53.

12 Nattress B R, Youngson C C, Martin D M, Cassidy M. Comparison of the quality of obturation following endosonic versus hand instrumentation. Int Endod $J$ 1994; 27: 178-183.

13 Marley J T, Ferguson D B, Hartwell G R. Effects of chlorhexidine gluconate as an endodontic irrigant on the apical seal: short-term results. J Endod 2001; 27: 775-778.

14 Timpawat S, Sripanaratanakul S. Apical sealing ability of glass ionomer sealer with and without smear layer. Endod 1998; 24: 343-345.

15 Hosoya N, Nomura M, Yoshikubo A, Arai T, Nakamura J, Cox C F. Effect of canal drying methods on the apical seal. J Endod 2000; 26: 292-294.

16 Bhambhani S M, Sprechman K. Microleakage comparison of thermafil versus vertical condensation using two different sealers. Oral Surg Oral Med Oral Pathol 1994; 78: 105-108.

17 Yared G M, Bou Dagher F. Sealing ability of the vertica condensation with different root canal sealers. J Endod 1996; 22: 6-8.

18 Siqueira F J Jr, Fraga R C, Garcia P F. Evaluation of sealing ability, $\mathrm{pH}$ and flow rate of three calcium hydroxide-based sealers. Endod Dent Traumatol 1995; 11: 225-228.

19 Goldberg F, Artaza L P, De Silvio A. Apical sealing ability of a new glass ionomer root canal sealer. J Endod 1995; 21: 498-500.

20 Limkangwalmongkol S, Abbott P V, Sandler A B. Apical dye penetration with four root canal sealers and gutta-percha using longitudinal sectioning. J Endod 1992; 18: 535-539.

21 Oguntebi B R, Shen C. Effect of different sealers on thermoplasticized Gutta-percha root canal obturations. J Endod 1992; 18: 363-366.

22 Mannocci F, Ferrari M. Apical seal of roots obturated with laterally condensed gutta-percha, epoxy resin cement, and dentin bonding agent. J Endod 1998; 24: 41-44.

23 Oliver C M, Abbott P V. Correlation between clinical success and apical dye penetration. Int Endod J 2001; 34: 637-644.

24 Saunders W P, Saunders E M. Coronal leakage as a cause of failure in root-canal therapy: a review. Endod Dent Traumatol 1994; 10: 105-108.

25 Heling I, Gorfil C, Slutzky H, Kopolovic K, Zalkind M, Slutzky-Goldberg I. Endodontic failure caused by inadequate restorative procedures: review and treatment recommendations. J Prosthet Dent 2002; 87: 674-678.

26 Trope M, Chow E, Nissan R. In vitro endotoxin penetration of coronally unsealed endodontically treated teeth. Endod Dent Traumatol 1995; 11: 90-94.

27 Alves J, Walton R, Drake D. Coronal leakage: endotoxin penetration from mixed bacterial 
communities through obturated, post-prepared root canals. J Endod 1998; 24: 587-591.

28 Torabinejad M, Ung B, Kettering J D. In vitro bacterial penetration of coronally unsealed endodontically treated teeth. J Endod 1990; 16: 566-569.

29 Swanson K, Madison S. An evaluation of coronal microleakage in endodontically treated teeth. Part I. Time periods. J Endod 1987; 13: 56-59.

30 Magura M E, Kafrawy A H, Brown C E Jr, Newton C W. Human saliva coronal microleakage in obturated root canals: an in vitro study. J Endod 1991; 17: 324-331.

31 Khayat A, Lee S J, Torabinejad M. Human saliva penetration of coronally unsealed obturated root canals. J Endod 1993; 19: 458-461.

32 Chailertvanitkul P, Saunders W P, MacKenzie D Weetman D A. An in vitro study of the coronal leakage of two root canal sealers using an obligate anaerobe microbial marker. Int Endod J 1996; 29: 249-255.

33 Chailertvanitkul P, Saunders W P, Mackenzie D. An assessment of microbial coronal leakage in teeth root filled with gutta-percha and three different sealers. Int Endod J 1996; 29: 387-392.

34 Ray H A, Trope M. Periapical status of endodontically treated teeth in relation to the technical quality of the root filling and the coronal restoration. Int Endod J 1995; 28: 12-18.

35 Fox K, Gutteridge D L. An in vitro study of coronal microleakage in root-canal-treated teeth restored by the post and core technique. Int Endod J 1997; 30: 361-368.

36 Fan B, Wu M K, Wesselink P R. Coronal leakage along apical root fillings after immediate and delayed post space preparation. Endod Dent Traumatol 1999; 15: 124-126.

37 Karapanou V, Vera J, Cabrera P, White R R, Goldman M. Effect of immediate and delayed post preparation on apical dye leakage using two different sealers. J Endod 1996; 22: 583-585.

38 Ewart A, Saunders W P. Investigation into the apical leakage of root-filled teeth prepared for a post crown. Int Endod J 1990; 23: 239-244.

39 Fan B, Wu M K, Wesselink P R. Leakage along warm gutta-percha fillings in the apical canals of curved roots. Endod Dent Traumatol 2000; 16: 29-33.

40 Ravanshad S, Torabinejad M. Coronal dye penetration of the apical filling materials after post space preparation. Oral Surg Oral Med Oral Pathol 1992; 74: 644-647.

41 Ricci E R, Kessler J R. Apical seal of teeth obturated by the laterally condensed guttapercha, the Thermafil plastic and Thermafil metal obturator techniques after post space preparation. J Endod 1994; 20: 123-126.

42 Kaplowitz G J. Evaluation of Gutta-percha solvents. J Endod 1990; 16: 539-540.

43 Brodin P, Roed A, Aars H, Orstavik D. Neurotoxic effects of root filling materials on rat phrenic nerve in vitro. $J$ Dent Res 1982; 61: 1020-1023.
44 Bourgeois R S, Lemon R R. Dowel space preparation and apical leakage. J Endod 1981; 7: 66-69.

45 Mattison G D, Delivanis P D, Thacker R W Jr, Hassell K J. Effect of post preparation on the apical seal. J Prosthet Dent 1984; 51: 785-789.

46 Haddix J E, Mattison G D, Shulman C A, Pink F E. Post preparation techniques and their effect on the apical seal. J Prosthet Dent 1990; 64: 515-519.

47 Goerig A C, Mueninghoff L A. Management of the endodontically treated tooth. Part II: Technique. J Prosthet Dent 1983; 49: 491-497.

48 Wagnild G W, Mueller K I. Restoration of the endodontically treated tooth. In Pathways of the Pulp. 7th Edition (Cohen S and Burns R C). St Louis: Mosby Inc, 1998. pp709.

49 Saunders E M, Saunders W P. The heat generated on the external root surface during post space preparation. Int Endod J 1989; 22: 169-173.

50 Tjan A H, Abbate M F. Temperature rise at root surface during post-space preparation. J Prosthet Dent 1993; 69: 41-45.

51 Hussey D L, Biagioni P A, McCullagh J J, Lamey P J. Thermographic assessment of heat generated on the root surface during post space preparation. Int Endod J 1997; 30: 187-190.

52 Camp L R, Todd M J. The effect of dowel preparation on the apical seal of three common obturation techniques. J Prosthet Dent 1983; 50: 664-666.

53 Raiden G C, Gendelman H. Effect of dowel space preparation on the apical seal of root canal fillings. Endod Dent Traumatol 1994; 10: 109-112

54 DeCleen M J. The relationship between the root canal filling and post space preparation. Int Endod J 1993; 26: 53-58.

55 Wu M K, Pehlivan Y, Kontakiotis E G, Wesselink P R. Microleakage along apical roo fillings and cemented posts. J Prosthet Den 1998; 79: 264-269.

56 Kvist T, Rydin E, Reit C. The relative frequency of periapical lesions in teeth with root canalretained posts. J Endod 1989; 15: 578-580.

57 Standlee J P, Caputo A A, Hanson E C. Retention of endodontic dowels: effects of cement, dowel length, diameter, and design. J Prosthet Dent 1978; 39: 400-405.

58 Goodacre C J, Spolnik K J. The prosthodontic management of endodontically treated teeth: a literature review. Part III. Tooth preparation considerations. J Prosthodont 1995; 4: 122-128.

59 Sorensen J A, Martinoff J T. Clinically significant factors in dowel design. J Prosthet Dent 1984; 52: 28-35

60 Ross I F. Fracture susceptibility of endodontically treated teeth. J Endod 1980; 6: 560-565.

61 Krupp J D, Caputo A A, Trabert K C, Standlee J P. Dowel retention with glass-ionomer cement. J Prosthet Dent 1979; 41: 163-166.

62 Hunter A J, Feiglin B, Williams J F. Effects of post placement on endodontically treated teeth. J Prosthet Dent 1989; 62: 166-172.

63 Trabert K C, Caput A A, Abou-Rass M. Tooth fracture-a comparison of endodontic and restorative treatments. J Endod 1978; 4: 341-345.
64 Deutsch A S, Musikant B L, Cavallari J, Silverstein L, Lepley J, Ohlen K, Lesser M. Root fracture during insertion of prefabricated posts related to root size. J Prosthet Dent 1985; 53: 786-789.

65 Abou-Rass M, Jann J M, Jobe D, Tsutsui F. Preparation of space for posting: effect on thickness of canal walls and incidence of perforation in molars. J Am Dent Assoc 1982; 104: 834-837

66 Tjan A H, Whang S B. Resistance to root fracture of dowel channels with various thicknesses of buccal dentin walls. J Prosthet Dent 1985; 53: 496-500.

67 Tilk M A, Lommel T J, Gerstein H. A study of mandibular and maxillary root widths to determine dowel size. J Endod 1979; 5: 79-82.

68 Hoag E P, Dwyer T G. A comparative evaluation of three post and core techniques. J Prosthet ent 1982; 47: 177-181.

69 Stankiewicz N R, Wilson P R. The ferrule effect: a literature review. Int Endod $\mathrm{J} 2002$; 35: 575-581.

70 Sorensen J A, Engelman M J. Ferrule design and fracture resistance of endodontically treated teeth. J Prosthet Dent 1990; 63: 529-536.

71 Rosen H, Partida-Rivera M. Iatrogenic fracture of roots reinforced with a cervical collar. Oper Dent 1986; 11: 46-50.

72 Barkhordar R A, Radke R, Abbasi J. Effect of metal collars on resistance of endodontically treated teeth to root fracture. J Prosthet Dent 1989; 61: 676-678.

73 Libman W J, Nicholls J I. Load fatigue of teeth restored with cast posts and cores and complete crowns. Int J Prosthodont 1995; 8 : 155-161.

74 Isidor F, Brondum K, Ravnholt G. The influence of post length and crown ferrule length on the resistance to cyclic loading of bovine teeth with prefabricated titanium posts. Int J Prosthodont 1999; 12: 78-82.

75 Nicholls J I. The dental ferrule and the endodontically compromised tooth. Quintessence Int 2001: 32: 171-173.

76 Torbjorner A, Karlsson S, Odman P A. Survival rate and failure characteristics for two post designs. J Prosthet Dent 1995; 73: 439-444.

77 Hemmings K W, King P A, Setchell D J. Resistance to torsional forces of various pos and core designs. J Prosthet Dent 1991; 66: 325-329.

78 Fugazzotto P A, Parma-Benfenati S. Preprosthetic periodontal considerations. Crown length and biologic width. Quintessence Int 1984; 15: 1247-1256.

79 Saupe W A, Gluskin A H, Radke R A Jr A comparative study of fracture resistance between morphologic dowel and cores and a resin-reinforced dowel system in the intraradicular restoration of structurally compromised roots. Quintessence Int 1996; 27: 483-491. 